\title{
Discussion on the Reform of Discrete Mathematics Teaching in Combination with Cases
}

\author{
Xue Xing \\ School of information and control engineering \\ Jilin Institute of Chemical Technology \\ Jilin, China
}

\author{
Bingtao Jin \\ School of information and control engineering \\ Jilin Institute of Chemical Technology \\ Jilin, China
}

\begin{abstract}
The traditional discrete mathematics teaching mode has not adapted to the needs of the training of applied talents at the present stage. Therefore, combining the practice case with the practice case, the students will connect the students to the knowledge and the application effectively. The students understand the theory on line and put forward solutions to the practical problems online. Discuss how to improve the method in the classroom. The feedback results show that the reform of this model is generally accepted by the students, and it is easier for students to master the practical application of the theory than the traditional model. In addition, the teaching design can be amended effectively through the feedback results of the practice of the teaching link, and the teaching reform is deepened.
\end{abstract}

Keywords-Flipped Classroom; Practice case; Discrete mathematics; Teaching model

\section{INTRODUCTION}

In the teaching process of traditional discrete mathematics, teachers often use the traditional teaching mode. The teaching process pays attention to the teaching and reasoning of theoretical knowledge, neglects the cultivation of ability and improves the accomplishment; the practice content and practice form are unchangeable, and the ability training of the application demand is ignored, which leads to the students to study the course[1]. The practical application is rather vague, and the use and significance of the learning are not high, so the learning interest is not high; the teaching design lacks innovative thinking and the deepening of the traditional theory teaching is ignored by the new research hot spots[2]. Therefore, how to make discrete mathematics get rid of the traditional "mathematics class" teaching mode, from the perspective of practical application, let the students connect the knowledge to the future application effectively, and become the key point of the reform of the discrete mathematics teaching in the current professional basic course.

\section{PRESENT SituAtion AND DeVElopment DiRECTION OF Discrete Mathematics TeACHING ReFORM}

Considering the important role of discrete mathematics courses in teaching and the status quo of students' learning, Prof. Qu Yuling from the School of Information Science and Technology of Peking University is aiming at the positioning of discrete mathematics courses in the professional curriculum system, combining the teaching objectives, teaching contents and teaching design of the curriculum. Etc. put forward the corresponding teaching implementation plan, propose a layered, modular knowledge framework, and provide basis for training students and curriculum construction according to the different training objectives of science, engineering and application. Reference [3] based on ongoing research, and designed to use the project-based-learning approach, the modules highlight applications of modern discrete mathematics and algebraic statistics to pressing problems in molecular biology. Reference [4] uesd discrete mathematics thinking and method to put together with the relevant curriculum theory and application to drive other relevant professional course study. Reference [5] claimed that teaching formal methods could be done at the undergraduate level by mixing formal methods and discrete mathematics courses and we illustrate such an approach with a small development within FoCaLiZe. Reference [6] and Reference [7] supplemented problem-based approach to teaching the course with a set of surveys or questionnaires that helped improve the students' performance.

\section{EXPLORATION ON THE TEACHING REFORM OF DisCRETE} Mathematics Flip ClassroOM With Practical Cases

\section{A. From "Classroom Teaching + Exercise Homework" to The Teaching Model of Flipping Classroom}

The discrete mathematics has many characteristics, such as many concepts, scattered content, highly theoretical and highly abstract, and most of the teachers adopt the traditional teaching mode, which is mainly based on theoretical teaching and exercise exercises supplemented by exercises. This model continues the students "previous "listening" as the main learning mode, unable to mobilize students' thinking forward and stimulate students' interest in solving problems.

In recent years, SPOC (Small Private Online Course) has developed rapidly in the field of higher education. As the characteristics of the discrete mathematics teaching fit the small-scale teaching mode, the emergence of the new teaching mode has a "qualitative" change to the teaching mode. But this way of learning does not make all the students understand the content of the course, so the teaching mode of the flipping course after the students' self - learning can show the students' understanding of the teaching content.

Flipping the classroom teaching mode requires teachers to modularize the curriculum in the form of knowledge points first, and abandon the original form of teaching units in class hours. The knowledge points are published in the form of video 
in the form of video on the campus education network platform. In the form of task, students can learn the core knowledge of the teaching in advance. Through the explanation of the students' understanding of their understanding and the knowledge of the form of thematic discussion in the classroom, the students can cultivate the students' comprehensive ability to express their views. Academic interest to enhance students' initiative in learning. From the teacher's side, teachers need to devote their time and energy to the students to understand the problems, explain the doubts and discuss new ideas, so as to achieve the good effect of teaching students in accordance with their aptitude. In addition, in the process of "turning", the subject of teaching has changed, and the students' selfunderstanding and expression may have two aspects. One is that the students' discussion of the discussion may be missing and wrong, and the students' own description can be fully reflected; two is the students' discussion of the core knowledge points. The ambiguous place, in fact, is that the students do not have a deep understanding of the knowledge, thus the teacher can through the students to express the problem in the middle of the discussion, from the students' deep understanding of the knowledge point. From the original teaching mode of "classroom teaching + Exercises" to the mode of overturning the classroom, the students from the original listening to the understanding of the learning process, change into self-learning to absorb, absorb to think, think to express, express to the deepening of the permeable learning process; teachers in the process of teaching the role of the process also Changes have taken place, from the incubator of original knowledge to the coordinators of learning resources and assistant partners in the learning process.

\section{B. Teaching methods from "concept + theory" to practical cases}

In the past teaching process, discrete mathematics is to define the interpretation and theorem analysis as the main teaching core. While students understand knowledge points, there are always some puzzles: "Where can all this content be used?" Students often can not see the specific application of discrete mathematics in computer science, and it is easy to lose interest in learning. This is not conducive to the explanation of follow-up knowledge, but also difficult to cultivate students' ability, but even online learning is mainly theoretical analysis.

With the emergence of this flexible teaching mode, flipped classroom has opened up a new way for teaching. On the basis of the problem of students, after the students' online learning, they take specific practical cases as their discussion questions. From the actual case, the students can feel the value of the theory application practice through the form of overturning the classroom. The following is to illustrate the specific application of case-based practice in the specific instructional design of knowledge point learning of the main disjunctive paradigm in propositional logic.

In order to enhance students' interest after online learning, circuit design examples are used as discussion questions. The problem is designed as "a bistable (high and low level) control circuit with three inputs of A, B and C and three outputs of FA, FB and FC respectively. Requirements: the input is low normal, no high-level output; at most, there is a high-level output; when

high level input, only the first high level input detected in the order of A, B, C is only effective, its corresponding output gets high level, and other output is suppressed at this time. Requirements: (1) Write the logical expressions describing the above three outputs respectively; (2) Build the logic circuits with and without gates to achieve the above control requirements. The discussion of the problem is combined with the content of this knowledge point and needs to be applied to the practice of the design of the circuit. The most important thing is to provide the application of the soil for the students to study the theory at the same time, so that the students can find the application and operation of the theory. Students can design the theory and design the "second classroom" practice platform in our school. In the classroom, many groups of students share the basic flow and basic design principles of the design, that is, using the true value table (as shown in Table 1) the main disjunctive normal form (logical expression) of the logical element (1) (2) (3) As shown, the design of the available logic circuit is further simplified, such as Formula (4) (5) (6), where $\uparrow$ denotes use and non-gate.

\section{TABLE I. INST ANCE TRUTH TABLE}

\begin{tabular}{cccccc|cccccc}
\hline $\mathrm{A}$ & $\mathrm{B}$ & $\mathrm{C}$ & $\mathrm{F}_{\mathrm{A}}$ & $\mathrm{F}_{\mathrm{B}}$ & $\mathrm{F}_{\mathrm{C}}$ & $\mathrm{A}$ & $\mathrm{B}$ & $\mathrm{C}$ & $\mathrm{F}_{\mathrm{A}}$ & $\mathrm{F}_{\mathrm{B}}$ & $\mathrm{F}_{\mathrm{C}}$ \\
\hline 0 & 0 & 0 & 0 & 0 & 0 & 1 & 0 & 0 & 1 & 0 & 0 \\
0 & 0 & 1 & 0 & 0 & 1 & 1 & 0 & 1 & 1 & 0 & 0 \\
0 & 1 & 0 & 0 & 1 & 0 & 1 & 1 & 0 & 1 & 0 & 0 \\
0 & 1 & 1 & 0 & 1 & 0 & 1 & 1 & 1 & 1 & 0 & 0 \\
\hline
\end{tabular}

The main disjunctive normal form of FA, FB and FC can be easily written from truth table.

$$
\begin{aligned}
& \mathrm{FA}=(\mathrm{A} \wedge \neg \mathrm{B} \wedge \neg \mathrm{C}) \vee(\mathrm{A} \wedge \neg \mathrm{B} \wedge \mathrm{C}) \vee(\mathrm{A} \wedge \mathrm{B} \wedge \neg \mathrm{C}) \vee(\mathrm{A} \wedge \mathrm{B} \\
& \wedge \mathrm{C}) ;
\end{aligned}
$$

$$
\mathrm{FB}=(\neg \mathrm{A} \wedge \mathrm{B} \wedge \neg \mathrm{C}) \vee(\neg \mathrm{A} \wedge \mathrm{B} \wedge \mathrm{C}) ;
$$

$$
\mathrm{FC}=\neg \mathrm{A} \wedge \neg \mathrm{B} \wedge \mathrm{C} ;
$$

The expression after the simplification is :

$$
\mathrm{FA}=\mathrm{A}=(\mathrm{A} \uparrow \mathrm{A}) \uparrow(\mathrm{A} \uparrow \mathrm{A}) ;
$$

$\alpha+\beta=\chi$. 


$$
\begin{array}{r}
\mathrm{FB}=\neg \mathrm{A} \wedge \mathrm{B}=(\mathrm{A} \uparrow \mathrm{A}) \wedge \mathrm{B}=((\mathrm{A} \uparrow \mathrm{A}) \uparrow \mathrm{B}) \uparrow((\mathrm{A} \uparrow \mathrm{A}) \uparrow \mathrm{B}) ;(5) \\
\alpha+\beta=\chi .
\end{array}
$$

$$
\begin{array}{r}
\mathrm{FC}=\neg \mathrm{A} \wedge \neg \mathrm{B} \wedge \mathrm{C}=(\mathrm{A} \uparrow \mathrm{A}) \wedge(\mathrm{B} \uparrow \mathrm{B}) \wedge \mathrm{C}=\cdots \cdots, \quad(6) \\
\alpha+\beta=\chi .
\end{array}
$$

There are many logical transformation that can be reduced in the process of practice, but the basic steps of the students in the discussion are the disjunctive paradigm based on true value representation, and the flexible design process makes the students master the application of the paradigm.

\section{The basic thinking of the reform of discrete mathematics teaching in combination with practical cases}

After in-depth analysis of the flipped classroom and proper selection of practical cases, the author combines the characteristics of "discrete mathematics" course, puts forward the basic idea of carrying out the teaching reform of "discrete mathematics" flipped classroom based on practical cases, and the specific process is shown in Fig. 1. Due to the uncertain acceptance of the change of teaching mode by the students during the exploratory period of teaching reform, it is not suitable to put all the class hours into the pilot program. In addition, we choose the flip-flop classroom to adopt the online and offline teaching mode, and use the feasibility of practical cases to implement teaching design, adopt flexible and diversified evaluation system, which fully reflects the students' Online Autonomous Learning Performance under the flip-flop classroom mode. Finally, through the evaluation experience of the feedback teaching mode reform at the end of the term, it provides a basis for further teaching reform.

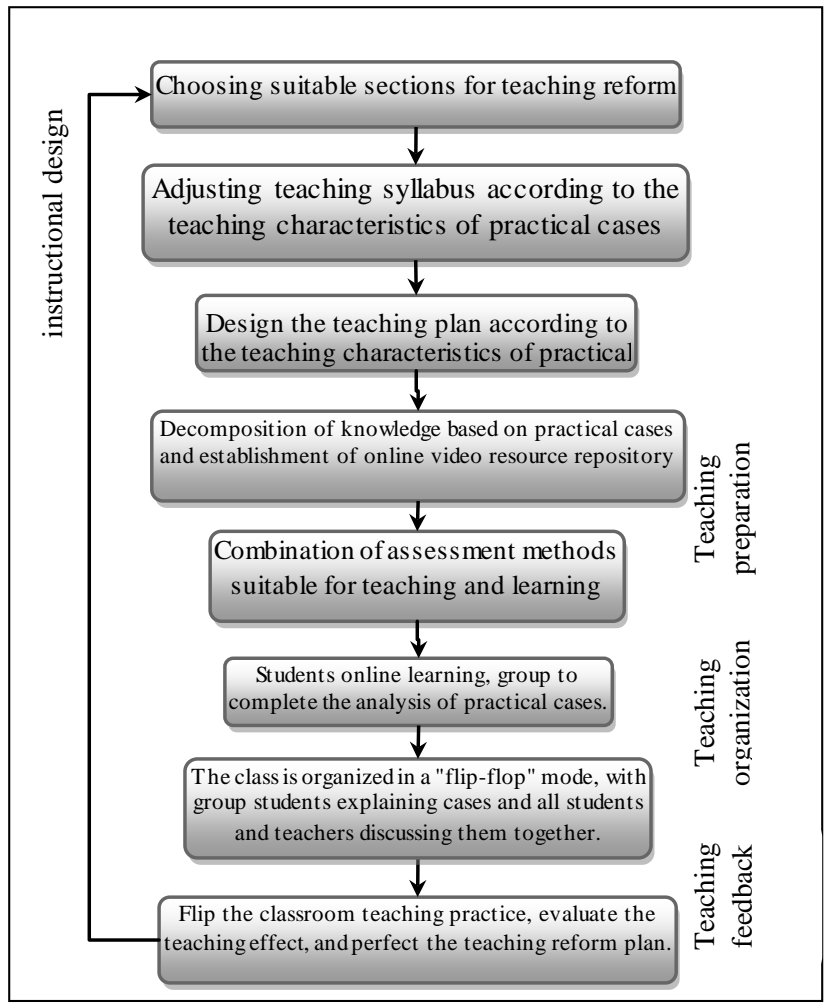

Fig. 1. Basic thinking of "discrete mathematics" flipped classroom teaching reform based on practical cases.

\section{FeEdBaCK ANAlysis of Specific Teaching RESEARCH AND EXPLORATION}

After teaching practice, students' feedback on curriculum reform was collected through online questionnaires. 119 questionnaires were collected from students of computer science and technology who participated in teaching reform. The survey questions include: (1) the change of teaching mode and the degree of acceptance after the course is over; (2) the role of practical cases in mastering one's own knowledge; (3) the degree of mastery of knowledge points in reversal teaching; (4) the degree of difficulty in mastering knowledge compared with traditional teaching; (5) the preparation time for discussion; (6) satisfaction with the material of the group members. The percentages of the survey data are shown in Fig. 2. 

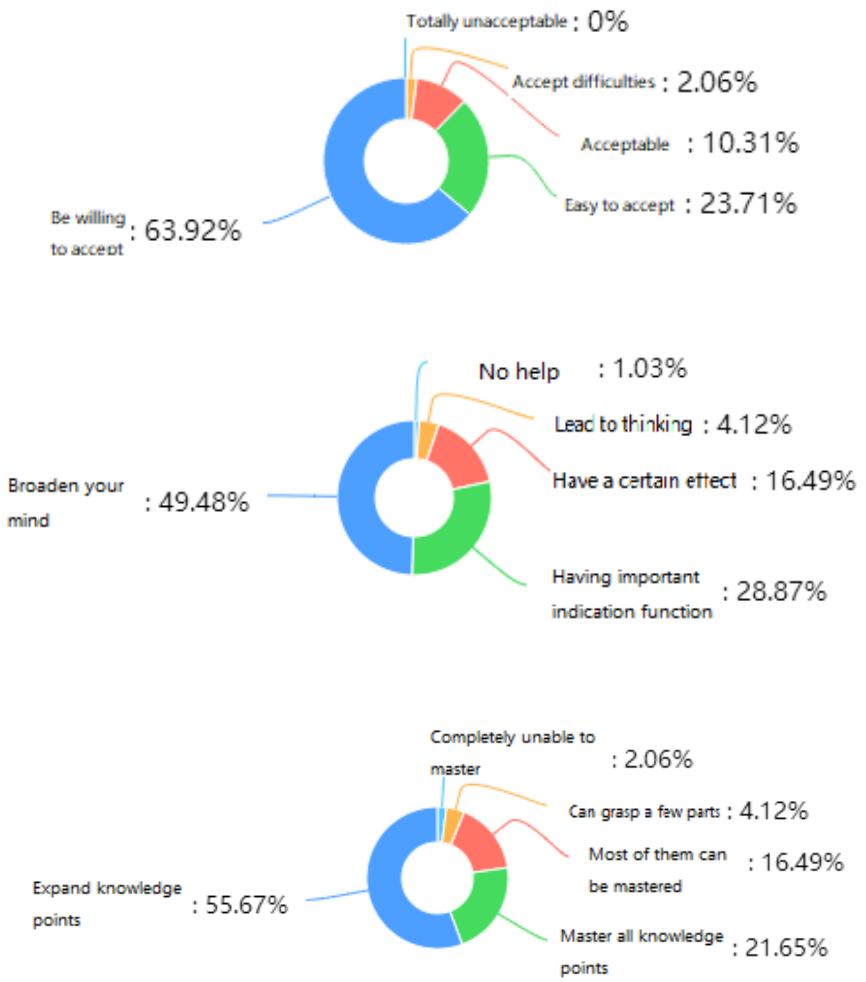

$58.76 \%$

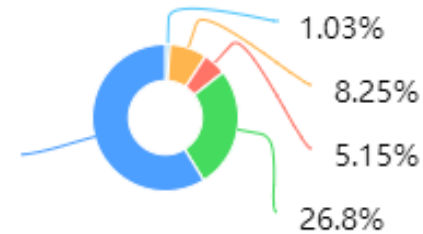

Harder than before

Consistent than before

More easier than before
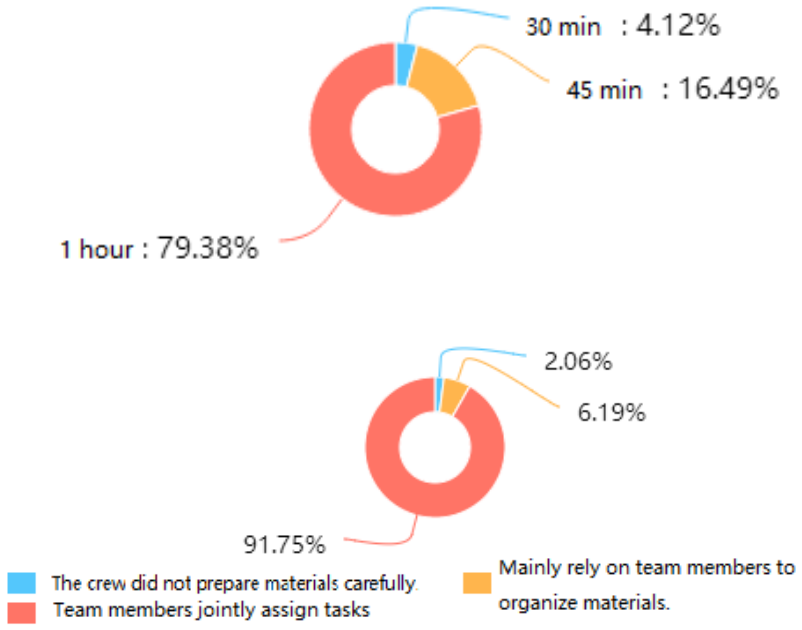

and organize materials.

Fig. 2. Percentage chart of survey results(feedback questions).
Based on the data obtained from the survey, this paper analyzes the relationship between the degree of change in teaching mode and the time spent in learning ,as shown in Fig. 3 , the sharing of other students in the teaching process and the difficulty of mastering knowledge under the new teaching mode ,as shown in Fig. 4. From the data chart, it can be seen that the students' acceptance of the teaching reform is higher than $87 \%$, and the higher the acceptance of the teaching model in the flipped classroom, the more time the students devote to discussing the problem, so the number of practical cases will be increased in the subsequent teaching design, and the students' acceptance of the new teaching model will be enhanced. At the same time, $78.35 \%$ of the respondents think that practical cases are helpful to the mastery of teaching knowledge, and in Fig. 4, it can be seen that the difficulty of mastering knowledge increases with the acceptance of practical cases by the respondents. Sexual function.

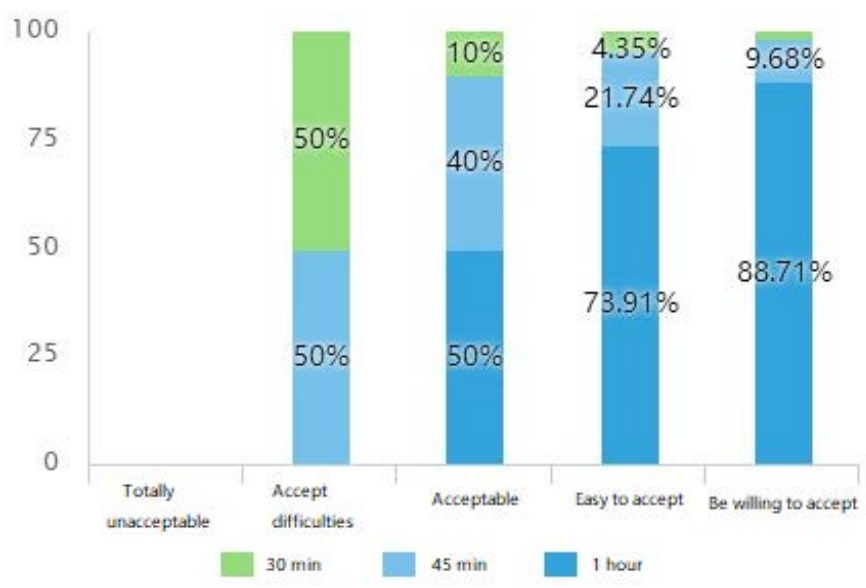

Fig. 3. Acceptance and input learning time

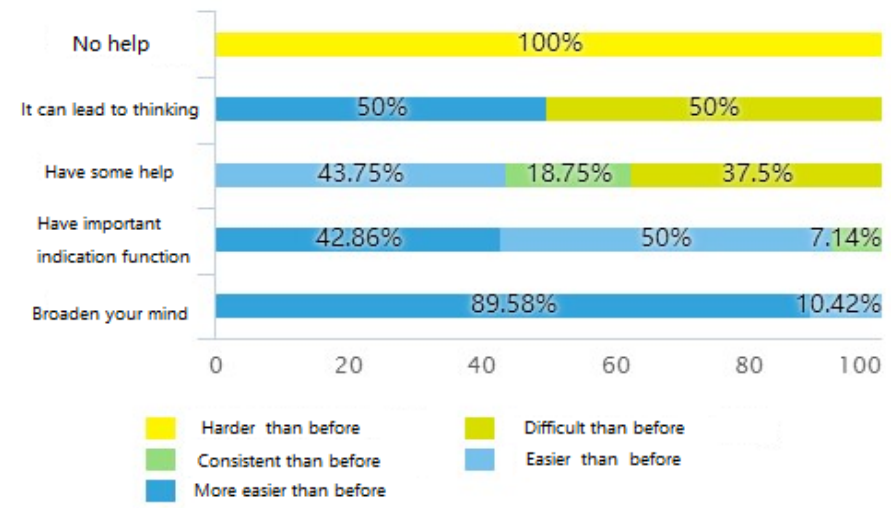

Fig. 4. Acceptance and knowledge points

\section{CONCLUSION}

The traditional concept of "concept + theory" as the teaching center, the teaching concept of "classroom teaching + problem-solving homework" as the main means, cannot adapt to the current application-oriented talent training needs, shackles the initiative of students' practice, and combines the practice case of flipping classroom teaching. From the perspective of practical application, the model allows students 
to effectively link their knowledge with subsequent applications. Students can understand the theory online, propose solutions to practical problems online, and discuss perfect methods in the classroom to highlight students' learning. The dominant position plays an important role in the cultivation of students' application ability.

\section{REFERENCES}

[1] W. Xubo and W. Yingfeng, "Research on Discrete Mathematics Teaching of IT Related Majors ", Computer education, vol.04, pp. 16-20, 2016.(in Chinese)

[2] O. A. Ivanov V. V. Ivanova and A. A. Saltan, "Discrete mathematics course supported by CAS mathematica", International Journal Of
Mathematical Education In Science And Technology, vol. 48, pp.953963,2017.

[3] R. Robeva, R. Davies, T. Hodge, and A. Enyedi, "Mathematical Biology Modules Based on Modern Molecular Biology and Modern Discrete Mathematics" ,Cbe-Life Sci Educ, vol.9, 227-240, 2010.

[4] J. Yuan,M. Yang, "Discrete mathematics as bridge for software engineering courses teaching and practice" .Melbourne, VIC, Australia, 2012, pp. 1987-1989.

[5] M. Jaume,T. Laurent, "Teaching formal methods and discrete mathematics ",Grenoble, France, 2014, pp. 30-43.

[6] M. Durcheva and E. Varbanova, "Applications of CAS in the Teaching and Learning of Discrete Mathematics," Mathematics in Computer Science, vol. 11, pp.305-314, 2017.

[7] O. A. Ivanov V. V. Ivanova and A. A. Saltan, "Likert-scale questionnaires as an educational tool in teaching discrete mathematics", International Journal of Mathematical Education in Science and Technology, vol.49, pp.1110-1118, 2018. 